\title{
Decreased aggressive and social responsiveness of chronically anosmic male rats
}

\author{
KEVIN J. FLANNELLY and ROBERT J. BLANCHARD \\ University of Hawaii, Honolulu, Hawaii 96822
}

\begin{abstract}
Sexually experienced male rats, injected intranasally with $\mathrm{ZnSO}_{4}$ solution, showed decreased social investigation toward juvenile and adult conspecifics of either sex, when tested 2 months posttreatment. Saline-treated control males exhibited levels of social-investigatory behavior toward juveniles similar to those displayed toward adult nonreceptive females. Copulatory attempts and aggression toward juveniles was minimal, with intense aggression against adult males exhibited by controls but not by anosmic subjects. Anosmic and control subjects showed comparable frequencies of mounting adults of both sexes. The results emphasize the importance of olfaction in social recognition and the differential effects of olfactory loss upon copulatory and aggressive behavior.
\end{abstract}

In rodents, the meeting of two unfamiliar conspecifics is characterized by the display of a number of species-typical behaviors. These social-investigatory behaviors include bodily contact, sniffing of different body areas, especially the perineal region, and mutual grooming (Barnett, 1975; Blanchard \& Blanchard, 1977; Christiansen \& Doving, 1976; Grant \& Mackintosh, 1963; Reynierse, 1971). During this preliminary investigation, which is usually the precursor of either aggressive or copulatory acts between adults, each animal apparently determines the sex, the reproductive state, and, possibly, the social status of the other. Several studies have shown that the nature of the terminal response (copulation or aggression) of this investigatory sequence is primarily determined by olfactory cues (Flannelly \& Thor, 1976; Jones \& Nowell, 1975; Payne, 1974).

The degree of adult social responsiveness toward juveniles of the same species has not been systematically examined in rodents. Barnett (1967) suggests that, in the rat, unfamiliar juveniles are ignored by adult males. Other studies have determined that some changes in the social response of the rat toward unfamiliar 5- to 25day-old juveniles are under olfactory control (Meyer, 1964; Paul \& Kupperschmidt, 1975), and some changes in social investigation of older juveniles have been reported (Thor, 1980).

The purpose of the present study was to compare the social responsiveness (including sexual and aggressive behavior) of anosmic and intact adult male rats toward conspecific adults and juveniles of each sex.

\section{METHOD}

\section{Animals}

Eight sexually experienced male rats of the Long-Evans strain, weighing $440-545 \mathrm{~g}$, were used as subjects. Thirty-two males and 32 females of the same strain were used as stimulus animals. Half of the stimulus animals were adults (100120 days old) and half were juveniles (30-40 days old). Weight ranges of each category were as follows: juvenile females, $100-155 \mathrm{~g}$; juvenile males, $100-165 \mathrm{~g}$; adult females, $305-450 \mathrm{~g}$; adult males, $430-500 \mathrm{~g}$. All stimulus animals were housed in like-sex groups of four to six animals. The eight adult males used as subjects were housed individually in $41 \times 51 \times 22 \mathrm{~cm}$ polypropylene pan cages for 2 weeks before testing. Food (Purina Chow) and water were freely available, and illumination was on a reversed $12 \mathrm{~h} / 12 \mathrm{~h}$ daily light-dark schedule throughout.

\section{Procedure}

Anosmia treatment. Two months prior to testing, subjects received a 3-day regimen of multiple intranasal applications of either isotonic $(.9 \%)$ saline $(n=4)$ or isotonic $(7.65 \%) \mathrm{ZnSO}_{4}$ $(n=4)$ solution. Under light ether anesthesia, a polypropylene tube was inserted $2 \mathrm{~cm}$ into the nares and $.2 \mathrm{ml}$ of solution was slowly syringed into the nasal cavity. During injection and recovery from anesthesia, the animal was held head downward to permit drainage of the solution onto an absorbent towel. $\mathrm{ZnSO}_{4}$ or placebo injections were repeated at $2 \mathrm{~h}$ intervals three times daily. See Thor and Flannelly (1977a) for further details of the application technique.

Anosmia test. One week prior to testing social responsiveness ( 2 months posttreatment), subjects were tested to determine latency to withdraw (turn $180 \mathrm{deg}$ ) from an aversive odorant (10\% ammonium hydroxide solution) in comparison with female urine and distilled water. Similar methods of assessing olfactory discrimination have been described by Benuck and Rowe (1975), Latané, Joy, Meltzer, and Lubell (1972), and Thor and Flannelly (1977a). Each subject was placed in a clear plastic box $(20 \times 10 \times 12 \mathrm{~cm})$ with a top that allowed the introduction of cotton swabs at either end of its long axis. A freshly dipped swab was placed about $1 \mathrm{~cm}$ from the tip of the nose, where it was maintained for $15 \mathrm{sec}$ or until the subject turned. Subjects usually oriented themselves on the long axis of the box but displayed occasional spontaneous 180 -deg turns. Stimuli were presented only when an animal was facing forward and immediately following a spontaneous turn. At least one spontaneous 180-deg turn occurred between each stimulus presentation. Subjects were tested once each day for 5 days, with each stimulus presented once during a test session. Order of stimulus presentation was randomly determined for each daily session.

Social behavior test. Testing was conducted in each subject's home cage. On the 1st day of testing, each subject was given 10 -min exposure to each of the four types of stimulus animals. 
Order of presentation was prearranged according to a Latin square, with a 10-min interval between tests. Subjects were tested again the following day (each subject was therefore tested twice with each type of stimulus animal). Each stimulus animal was used only once. During the $10-\mathrm{min}$ exposure, frequencies of the male subject's social-investigatory, sexual, and aggressive behaviors toward the stimulus animal were recorded (Blanchard \& Blanchard, 1977; Grant \& Mackintosh, 1963).

\section{RESULTS}

\section{Social Behavior Test}

Figure 1 presents the group mean frequencies of anosmic and control subjects'social, sexual, and aggressive responses during 10-min exposures to each type of

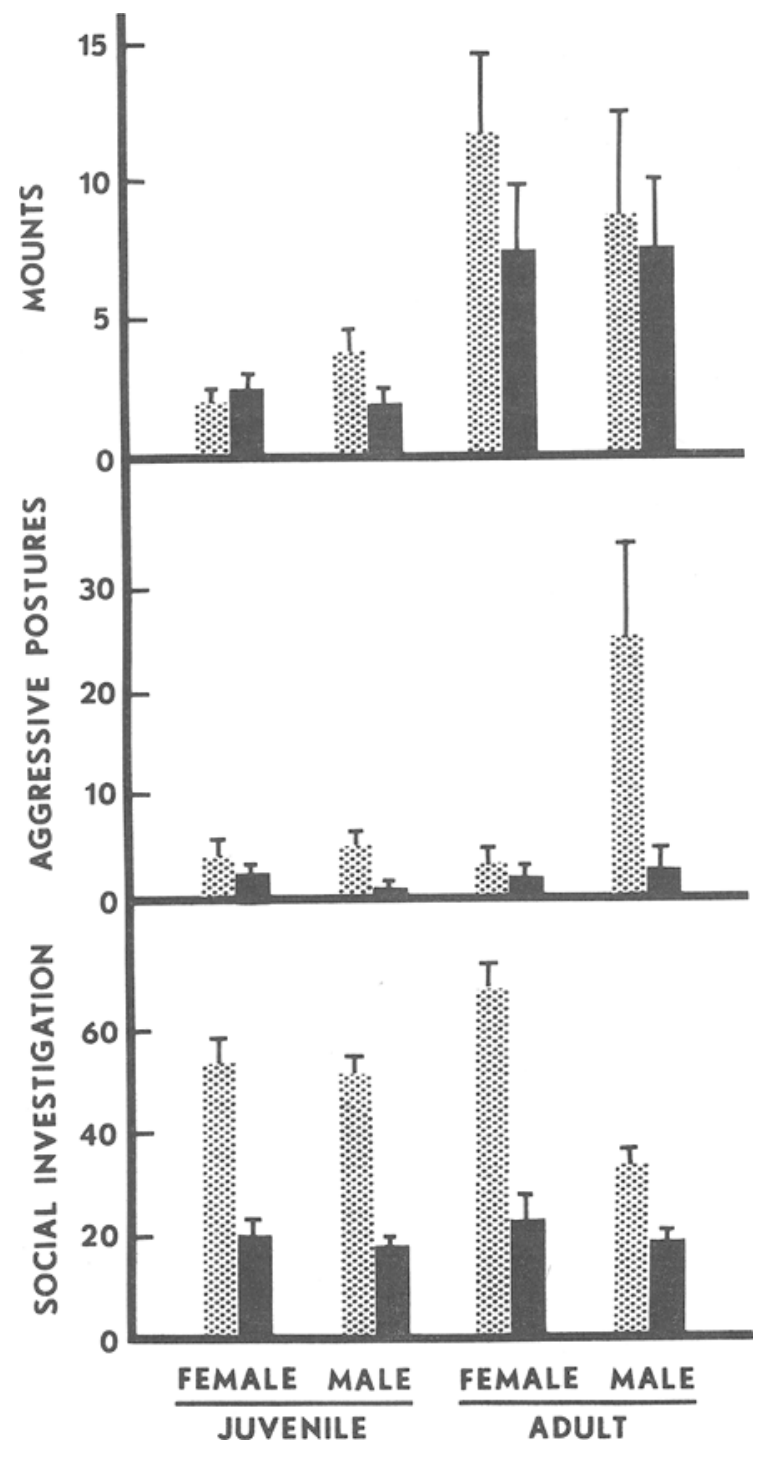

Figure 1. Mean (and standard error) frequency of male responding during $10-\mathrm{min}$ exposures to each of four types of stimulus animals. Black bars indicate $\mathrm{ZnSO}_{4}$-treated animals; speckled bars indicate saline-treated controls. stimulus animal. A 2 (sensory treatment) by 2 (size of stimulus animal) by 2 (sex of stimulus animal) by 2 (test day) ANOVA was performed on each measure. The main effect of sensory treatment was significant for social investigation $[\mathrm{F}(1,6)=17.13, \mathrm{p}<.01]$ and aggressive posturing $[\mathrm{F}(1,6)=8.35, \mathrm{p}<.05]$, but nonsignificant for mounts. Only size of stimulus animals was found to have a significant effect on mounting behavior $[F(1,6)=8.06, p<.05]$, with adult animals mounted more frequently. No subject achieved intromission, and no stimulus females displayed lordosis or proceptive behaviors. Significant interactions of Size by Sex $[F(1,6)$ $=11.21, \mathrm{p}<.01]$ and Sensory Treatment by Size by Sex $[F(1,6)=7.41, p<.05]$ were found for social investigation. These interactions represent certain obvious characteristics of the response of control subjects: an enhanced social response toward adult females compared with that exhibited toward juveniles of either sex, and reduced levels of social investigation toward males. The interaction of Sensory Treatment by Size by Test Day $[F(1,6)=9.92, p<.05]$ was also significant for the social investigation measure. The response of saline-treated subjects toward juveniles increased from the 1st to 2nd day of testing, as did the response of $\mathrm{ZnSO}_{4}$-treated subjects toward adults. No other main effects or interactions were significant for this or the other two measures.

Females, in general, were approached, followed, and sniffed more frequently than were males. Anogenital sniffing of adult females was only slightly greater than that shown toward juveniles. Saline-treated subjects displayed a slight decline in anogenital sniffing of adults from the 1 st to the 2 nd day of testing, whereas their frequency of anogenital sniffing of juveniles increased appreciably on the 2 nd test day. Anogenital sniffing by anosmic males was minimal toward all groups throughout testing and did not change over days.

As seen in Figure 1, intact subjects showed considerable aggression toward intact males placed into their home cages. Intact subjects showed at least one bite attack in every test with an adult male intruder. No other stimulus animal was ever bitten. In contrast to the aggressive response of these subjects, anosmic subjects showed virtually no aggressive responding toward other adult males. No anosmic male showed offensive sideways posture (or lateral attack) or attacked any stimulus animal, even though testing was conducted 2 months after $\mathrm{ZnSO}_{4}$ treatment.

\section{Anosmia Test}

Mean latencies to withdraw (turn $180 \mathrm{deg}$ ) from each type of stimulus are given in Table 1. A 2 (sensory treatment) by 3 (type of stimulus) by 5 (days of testing) ANOVA was performed upon the latency scores. The effect of type of stimulus $[F(2,12)=8.90, p<.01]$ and interaction of Sensory Treatment by Type of Stimulus $[F(2,12)=19.21, p<.01]$ were significant, with the 
Table 1

Means and Standard Errors of Zinc- and Saline-Treated Groups' Withdrawal Latency From Ammonium Hydroxide and Control Solutions

\begin{tabular}{|c|c|c|c|c|}
\hline \multirow[b]{3}{*}{ Stimulus Solution } & \multicolumn{4}{|c|}{ Group } \\
\hline & \multicolumn{2}{|c|}{ Saline } & \multicolumn{2}{|c|}{ Zinc } \\
\hline & Mean & SE & Mean & SE \\
\hline Ammonium Hydroxide & 5.9 & 1.9 & 12.6 & 1.5 \\
\hline Female Urine & 13.7 & 1.4 & 11.7 & 2.1 \\
\hline Distilled Water & 12.9 & 1.7 & 10.4 & 1.9 \\
\hline
\end{tabular}

$\mathrm{ZnSO}_{4}$-treated group showing a greater mean latency to withdraw from the ammonium hydroxide solution than saline-treated controls. Withdrawal latencies for the other two stimuli were comparable for the two groups, and no other main effects or interactions were significant. When failing to turn away from the ammoniasoaked swabs, $\mathrm{ZnSO}_{4}$-treated subjects typically exhibited facial grooming and digging movements. Salinetreated subjects similarly performed facial grooming upon exposure to the ammonia, but they did so only briefly before turning away from the swab. The prolonged withdrawal latencies of $\mathrm{ZnSO}_{4}$-treated subjects demonstrated their loss of olfactory ability to spatially localize the irritant source.

\section{DISCUSSION}

All four types of stimulus animals elicited social-investigatory behavior from intact male subjects. Investigation of adult males was only preliminary to aggressive attack by saline-treated subjects, whereas social investigation of females was more sustained throughout the test session. Although juveniles between 20 and 40 days of age do not elicit aggression (Meyer, 1964; Thor \& Flannelly, 1976) or copulation, they do appear to elicit normal social investigation (see Figure 1). This finding is in disagreement with the observation of Barnett (1967) that immature conspecifics entering a strange territory are ignored by adult males. Social investigation appears essential in determining sex and reproductive status of an unfamiliar animal, and consequently, it is displayed toward all animals entering another's territory. While adult females may be investigated quite thoroughly by a territorial resident to assess their reproductive status, unfamiliar males are quickly discerned and attacked by resident males with little investigation thereafter (Blanchard \& Blanchard, 1977). This is especially true if male residents have extensive experience with intruders (Blanchard, Takahashi, \& Blanchard, 1977).

Dixon and Mackintosh (1976) have reported that adult male mice respond differentially to the odors of juvenile conspecifics of either sex. Specifically, the urine of juvenile females placed on the coats of adult males that were used as stimulus animals inhibited attack against these males, whereas stimulus males treated with the urine of male juveniles were vigorously attacked. While both male and female juveniles were themselves free from aggressive assault by males, the results suggest that juvenile females possess a sex-identifying scent capable of inhibiting male aggression. Taylor (Note 1) similarly reports the capacity of juvenile mouse urine to inhibit aggression, but since this effect was not restricted to female urine, no evidence of sex-identifying odors in juveniles is indicated. The present findings fail to demonstrate discrimination of the sex of juvenile conspecifics by adult male rats. Differential responding toward juvenile males and females was not anticipated in the present study, since recognition of maleness, at least, is dependent upon changes in gonadal function associated with puberty (Flannelly \& Thor, 1978; Thor \& Flannelly, 1976). As such, the lack of aggression exhibited toward juvenile rats by adult male conspecifics need not be attributed to a process of active aggressive inhibition.

As found in previous studies using sexually naive subjects (Flannelly \& Thor, 1976; Thor \& Flannelly, 1977b), intranasal applications of $\mathrm{ZnSO}_{4}$ solution significantly decreased all measures of male social investigation. The length of time ( 2 months) between treatment and testing likely precludes the possibility that residual effects of toxicity produced by $\mathrm{ZnSO}_{4}$ treatment can account for the reduced social investigation of experimental subjects. Further, the results of the anosmia tests (see Table 1) support the assumption that $\mathrm{ZnSO}_{4}$-treated animals were anosmic at the time of behavioral testing. The observed reduction in social-investigatory behaviors toward conspecifics thus appears to result solely from loss of olfactory ability. Despite the failure of some researchers (e.g., Soltnick \& Gutman, 1977; Stone, 1941) to produce peripheral olfactory deficits adequate for behavioral research purposes using intranasal administration of $\mathrm{ZnSO}_{4}$ solution, an abundance of findings indicate its utility in this regard. There is now clear behavioral evidence of prolonged peripheral anosmia of up to 2 month's duration in rats and mice (Flannelly, Dupree, \& Thor, 1977; Harding, Getchell, \& Margolis, 1978; Thor \& Flannelly, 1977a). These data are further supported by histological findings of extensive destruction of the nasal epithelium, atrophy of the olfactory bulbs, and associated biochemical alteration of the olfactory pathway following multiple intranasal applications of $\mathrm{ZnSO}_{4}$ solution (Harding et al., 1978; Harding \& Margolis, 1976; Margolis, Roberts, Ferriero, \& Feldman, 1974). In discussing the effects of $\mathrm{ZnSO}_{4}$ in mice, Harding et al. (1978, p. 282) comment that "although the olfactory mediated food-finding behavior ultimately returns to normal after many months, most of the biochemical and morphological changes observed are irreversible and only regain $5-10 \%$ of control values."

The present findings, in conjunction with previous research, indicate that social recognition in the rat is principally determined by olfactory cues. Loss of olfactory ability reduced social-investigatory behavior toward stimulus animals to comparably low levels regardless of sex or size. The results further support the contention that anosmia eliminates territorial aggression of resident male rats toward unfamiliar males (Alberts \& Galef, 1973; Flannelly \& Thor, 1976) as part of this reduced social responsiveness.

Finally, a certain basal level of copulatory responding (Figure 1) is apparently elicited from sexually experienced males by conspecifics of sufficient body size. This level of sexual responding persists in the absence of olfactory cues and may be exhibited by intact animals even when olfactory cues that elicit aggressive responding are present. While the anosmic males of the present study show slightly reduced levels of mounting, anosmic males with extensive sexual experience have been found to be highly persistent in repeated copulatory attempts with adult nonreceptive females (Thor \& Flannelly, 1978). In view of the variety of social information conveyed by olfaction in the rat (Carr, 1974), it may seem curious that mounting in this species may be elicited by the simple semblance of an adult conspecific (see Beach, 1942). Previous research, however, has shown that although olfactory stimuli are significant in the initiation of copulation by the male rat, nonolfactory cues suffice to maintain copulation in sexually experienced males (Bermant \& Taylor, 1969; Thor \& Flannelly, 1977c; Wilhelmsson \& Larsson, 1973). Indeed, following the loss of olfactory function, sexually experienced males are capable of adequately selecting estrous females from among other stimulus animals on the basis of nonolfactory cues (Thor \& Flannelly, 1978). 
Given the critical biological import of copulation, it is not surprising, therefore, that its manifestation is not strictly dependent upon particular sensory input (Beach, 1942). Aggression, on the other hand, is biologically functional only within a limited spatial and social context, and thus its initiation is under specific sensory control, namely, olfaction, in the rat.

\section{REFERENCE NOTE}

1. Taylor, G. T. Juvenile mouse urine as an aggression inhibitor. Paper presented at the annual meeting of the Psychonomic Society, Washington, D.C., November 1977.

\section{REFERENCES}

Alberts, J. R., \& Galef, B. G., JR. Olfactory cues and movement: Stimuli mediating intraspecific aggression in the wild Norway rat. Journal of Comparative and Physiological Psychology, 1973, 85, 233-242.

Barnett, S. A. Rats. Scientific American, 1967, $216,78-85$.

BARnetT, S. A. The rat: A study in behavior (rev. ed.). Chicago: University of Chicago Press, 1975.

BEACH, F. A. Analysis of the stimuli adequate to elicit mating behavior in the sexually inexperienced male rat. Journal of Comparative Psychology, 1942, 33, 163-207.

BenuCK, I., \& Rowe, F. A. Centrally and peripherally induced anosmia: Influences on maternal behavior in lactating female rats. Physiology \& Behavior, 1975, 14, 439-447.

Bermant, G., \& Taylor, L. Interactive effects of experience and olfactory bulb lesions in male rat copulation. Physiology \& Behavior, 1969, 4, 13-17.

Blanchard, R. J., \& Blanchard, D. C. Aggressive behavior in the rat. Behavioral Biology, 1977, 21, 197-224.

Blanchard, R. J., Takahashi, L. K., \& Blanchard, D. C. The development of intruder attack in colonies of laboratory rats. Animal Learning \& Behavior, 1977, 5, 365-369.

CARR, W. J. Pheromonal sex attractants in the Norway rat. In L. Krames, P. Pliner, \& T. Alloway (Eds.), Nonverbal communication. New York: Plenum, 1974.

Christiansen, E., \& Doving, K. B. Observations of the mating behavior of the bank vole, Clethrionomys glareolus. Behavioral Biology, 1976, 17, 263-266.

Dixon, A. K., \& Mackintosh, J. H. Olfactory mechanisms affording protection from attack to juvenile mice (Mus musculus L.). Zeitschrift für Tierpsychologie, 1976, 41, 225-234.

Flannelly, K. J., Dupree, D. A., \& Thor, D. H. Social responsiveness and $\mathrm{Zn}$-induced anosmia in rats: $\mathrm{A}$ replication. Bulletin of the Psychonomic Society, 1977, 10, 63-65.

Flannelly, K. J., \& Thor, D. H. Territorial behavior of laboratory rats under conditions of peripheral anosmia. Animal Learning \& Behavior, 1976, 4, 337-340.

Flannelly, K. J., \& ThOR, D. H. Territorial aggression of the rat to males castrated at various ages. Physiology \& Behavior, 1978, 20, 785-789.

Grant, E. C., \& Mackintosh, J. H. A comparison of the social postures of some common laboratory rodents. Behaviour, 1963, 21, 246-259.

Harding, J. W., Getchell, T. V., \& Margolis, F. L. Denervation of the primary olfactory pathway in mice: V. Long-term effects of intranasal $\mathrm{ZnSO}_{4}$ irrigation on behavior, biochemistry and morphology. Brain Research, 1978, 140, 271-285.

Harding, J., \& Margolis, F. L. Denervation in the primary olfactory pathway of mice: Effect on enzymes of carnosine metabolism. Brain Research, 1976, 110, 351-360.

JoNes, R. B., \& Nowell, N. W. Effects of clean and soiled sawdust substrates and of different urine types upon aggressive behavior in male mice. Aggressive Behavior, 1975, 1, 111-121.

Latané, B., Joy, V., Meltzer, J., \& Lubell, B. Stimulus determinants of social attraction in rats. Journal of Comparative and Physiological Psychology, 1972, 79, 13-21.

Margolis, F. L., Roberts, N., Ferriero, D., \& Feldman, J. Denervation in the primary olfactory pathway of mice: Biochemical and morphological effects. Brain Research, 1974, 81, 469-483.

MEYER, J. S. Stimulus control of mouse-killing rats. Journal of Comparative and Physiological Psychology, 1964, 58, 112-117.

PAUl, L., \& KuPPERschmidT, J. Killing of conspecific and mouse young by male rats. Journal of Comparative and Physiological Psychology, 1975, 88, 755-763.

Payne, A. P. The effects of urine on aggressive responses by male golden hamsters. Aggressive Behavior, 1974, 1, 71-79.

Reynierse, J. H. Agonistic behavior in Mongolian gerbils. Zeitschrift für Tierpsychologie, 1971, 29, 175-179.

Soltnick, B. M., \& Gutman, L. A. Evaluation of intranasal zinc sulfate treatment on olfactory discrimination in rats. Journal of Comparative and Physiological Psychology, 1977, 91, 942-950.

Stone, C. P. A simple method for developing olfactory discrimination habits in rats. Journal of Genetic Psychology, 1941, 58, 419-421.

Thor, D. H. Testosterone and persistence of social investigation in laboratory rats. Journal of Comparative and Physiological Psychology, 1980, 94, 970-976.

Thor, D. H., \& Flannelly, K. J. Age of intruder and territorialelicited aggression in male Long-Evans rats. Behavioral Biology, 1976, 17, 237-241.

Thor, D. H., \& Flannelly, K. J. Anosmia and toxicity of intranasal zinc. Physiological Psychology, 1977, 5, 261-269. (a)

ThoR, D. H., \& Flannelly, K. J. Peripheral anosmia and social investigatory behavior of the male rat. Behavioral Biology, 1977, 20, 128-134. (b)

Thor, D. H., \& Flannelly, K. J. Social-olfactory experience and initiation of copulation in the virgin male rat. Physiology \& Behavior, 1977, 19, 411-417. (c)

Thor, D. H., \& Flannelly, K. J. Sex-eliciting behavior of the female rat: Discrimination of receptivity by anosmic and intact males. Behavioral Biology, 1978, 23, 326-340.

Wilhelmsson, M., \& Larsson, $\mathrm{K}$. The development of sexual behavior in anosmic male rats reared under various social conditions. Physiology \& Behavior, 1973, 11, 227-232.

(Received for publication December 14, 1981.) 